\title{
Water intoxication in epileptic patients receiving carbamazepine
}

\author{
E. PERUCCA, A. G A R R A T , S. HE B D I G E, A N D A. R I CHE N S \\ From the Chalfont Centre for Epilepsy, Chalfont St Peter, Department of Chemical Pathology, \\ Wycombe General Hospital, High Wycombe, and the Clinical Pharmacology Unit, \\ Institute of Neurology, London
}

SUMMARY Plasma sodium and osmolality were determined in 80 adult epileptic patients receiving chronic treatment with carbamazepine and in 50 control patients treated with other anticonvulsant drugs. Mean plasma osmolality was significantly lower in the carbamazepinetreated patients but mean plasma sodium did not differ in the two groups. Hyponatraemia was found in five of the carbamazine-treated patients and hypo-osmolality in six. None of the control patients had hyponatraemia and only one had a borderline low osmolality. Three of the 13 patients receiving carbamazepine alone were hyponatraemic. Plasma sodium concentration correlated negatively with both daily carbamazepine dose and serum carbamazepine level. Free water clearance after an oral water load was determined in six patients on carbamazepine alone and in six normal subjects not receiving drug therapy. The capacity of some of the patients to excrete the water load was found to be grossly impaired.

Hyponatraemia and low plasma osmolality may occur in patients receiving carbamazepine for the treatment of epilepsy or trigeminal neuralgia (Rado, 1973; Ashton et al., 1977; Henry et al., 1977; Stephens et al., 1977). Although these authors report a number of cases of severe water intoxication, it is likely that in many patients asymptomatic electrolyte disturbances are unrecognised (Henry et al., 1977).

The antidiuretic effects of carbamazepine may have important clinical implications in the management of epilepsy. Water retention or excessive intake of fluids may precipitate seizures (McQuarrie, 1929), and it has been suggested that the disappointing therapeutic response to carbamazepine in some patients with epilepsy could be related to the occurrence of drug-induced electrolyte disturbances (Stephens et al, 1977). Moreover, the clinical manifestations of hyponatraemia (dizziness, headache, mental confusion, drowsiness, and nausea) are similar to the most common adverse effects of antiepileptic drugs, and it is

Address for reprint requests: Dr A. Richens, Clinical Pharmacology Unit, Institute of Neurology, The National Hospital, London WC1N 3BG.

Accepted_21 February_1978 possible that in some epileptic patients treated with carbamazepine the signs of water intoxication are mistakenly attributed to direct drug toxicity (Stephens et al., 1977).

Relatively little information, however, is available on the incidence of carbamazepine-induced hyponatraemia in epileptic patients. Henry et al. (1977) found five cases of hyponatraemia among 16 carbamazepine-treated patients with epilepsy or trigeminal neuralgia, and described a negative correlation between plasma sodium concentration and daily carbamazepine dose above $700 \mathrm{mg}$. On the other hand, none of the 26 carbamazepinetreated epileptic children studied by Helin et al. (1977) had abnormal levels of electrolytes.

In the present study we have determined plasma sodium and osmolality in a large population of epileptic patients receiving chronic treatment with carbamazepine. Fifty patients treated with other anticonvulsant drugs were included in the study as a control group. In order to investigate the integrity of the homeostatic mechanisms which regulate water balance during carbamazepine therapy, free water clearance after administration of a water load has been measured in a group of patients on carbamazepine and in a control group of normal subjects not receiving drug therapy. 


\section{Subjects and methods}

\section{EPIDEMIOLOGICAL STUDY}

All subjects were epileptic patients of the National Hospitals-Chalfont Centre for Epilepsy, Chalfont St Peter, Buckinghamshire. Eighty patients (51 men and 29 women) aged between 16 and 57 years and receiving chronic treatment with carbamazepine either alone (13 patients) or in combination with other antiepileptic drugs (in most cases phenytoin or phenobarbitone or both) were selected for the study. The carbamazepine dose ranged from 200 to $1800 \mathrm{mg} / \mathrm{day}$. Duration of treatment with the drug ranged from two weeks to five years. A similar group of 50 patients treated with anticonvulsants other than carbamazepine were included as a control group. A very small proportion of the patients studied were receiving drugs for conditions other than epilepsy-for example, chlorpromazine, haloperidol, antidepressants, antibiotics. To our knowledge, no patient was suffering from a condition or taking drugs known to influence electrolyte balance.

Fasting blood samples $(20 \mathrm{ml})$ were taken from each patient at $0700 \mathrm{~h}$ before the morning dose of the drugs. Plasma sodium concentration was determined by Auto-Analyser SMA 6/60 (Technicon), and plasma osmolality by a Precision Osmometer (Krauer). Analyses were performed within $10 \mathrm{~h}$ of sampling.

An aliquot of serum was kept frozen at $-20^{\circ} \mathrm{C}$ for subsequent measurement of carbamazepine concentration by enzyme immunoassay (EMIT, Syva Corporation, Palo Alto, California).

\section{WATER LOAD TESTS}

Six epileptic patients and six healthy drug-free subjects aged 19-36 years and matched for sex, age, and body weight volunteered to take part in the trial. The nature of the trial was fully explained to them. All epileptic patients were on chronic treatment with carbamazepine alone (dose range 600-1600 mg/day). Because water retention is known to precipitate fits, only patients with a normal plasma sodium concentration and osmolality under basal conditions and having mainly minor epileptic fits were included in the trial. Patients having frequent attacks or liable to severe generalised convulsions were excluded. On the day of the study the subjects presented themselves at 0700 after an overnight fast. The first dose of carbamazepine was administered as usual. After emptying their bladders completely, the subjects received an oral load of water $(20 \mathrm{ml} /$ $\mathrm{kg}$ up to a maximum of $1600 \mathrm{ml}$ ) over 30 minutes. They were asked to empty their bladders every 30 minutes for 3.5 hours. The volume of each urine specimen was measured and a $5 \mathrm{ml}$ sample kept for determination of osmolality. Blood samples $(20 \mathrm{ml})$ were taken immediately before and at the end of the test for estimation of plasma sodium concentration and osmolality. The free water clearance $\left(\mathrm{Cl}_{\mathrm{H}_{2} \mathrm{O}}\right)$ was calculated from the urine flow (V) and the osmolal clearance $\left(\mathrm{Cl}_{\text {osm }}\right)$ accordto the formula:

$$
\begin{aligned}
& \mathrm{Cl}_{\mathrm{H}_{2} \mathrm{O}}=\mathrm{V}-\mathrm{Cl}_{\mathrm{osm}} \\
& \mathrm{Cl}_{\text {osm }} \text { was calculated as: } \frac{\text { urine osmolality }}{\text { plasma osmolality }} \times \mathrm{V}
\end{aligned}
$$

No serious adverse effects were encountered. Two patients complained of general malaise and drowsiness during the test, and one of them had a fit with prolonged automatisms at the end of the test. These symptoms cleared after the profuse diuresis which followed oral administration of frusemide $(80 \mathrm{mg})$. No other adverse effects were observed.

\section{Results}

EPIDEMIOLOGICAL STUDY

The distribution frequency of plasma sodium concentration and osmolality in the patients included in the study are illustrated in Figs. 1 and 2. Low plasma sodium concentration (below $135 \mathrm{mmol} / \mathrm{l}$ ) was found in five patients on carbamazepine and in none of the patients on other antiepileptic drugs. Low osmolality (below $265 \mathrm{mosm} / \mathrm{kg}$ ) was found in six of the carbamazepine-treated patients. One patient had a borderline low osmolality in the control group. Details of the five hyponatraemic patients are given in the Table. Three of them were on carbamazepine alone.

Mean plasma sodium concentration in the patients on carbamazepine did not differ from that of the control group $(139.9 \pm 3.7 \mathrm{SD}$ and $139.9 \pm$ $2.1 \mathrm{mmol} / 1$ respectively). However, plasma osmolality was significantly lower in the patients on

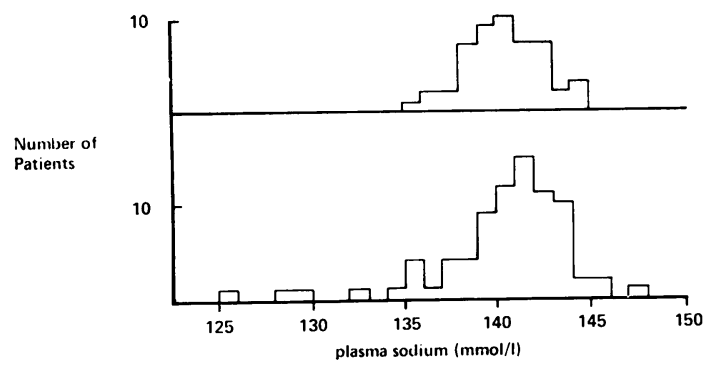

Fig. 1 Distribution of plasma sodium concentrations in 80 epileptic patients on carbamazepine (bottom) and in 50 patients on other antiepileptic drugs (top). 


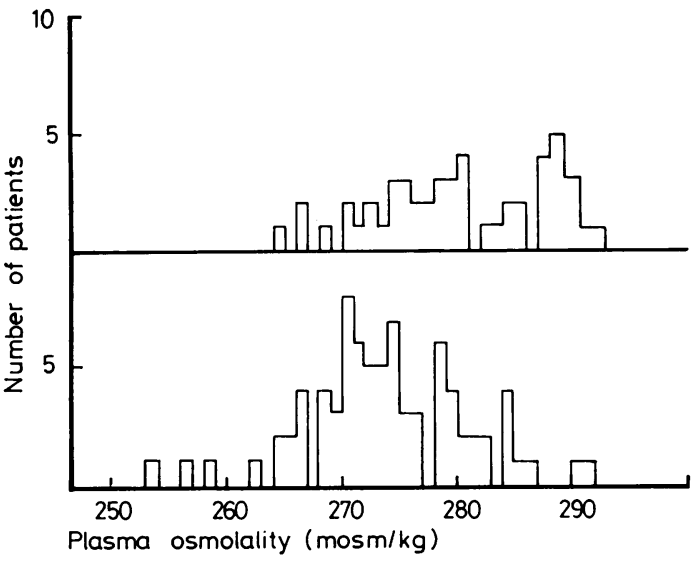

Fig. 2 Distribution of plasma osmolality in 80 epileptic patients on carbamazepine (bottom) and in 50 patients on other antiepileptic drugs.

carbamazepine compared with the control subjects $(273.7 \pm 7.2 \mathrm{SD}$ and $279.5 \pm 7.3 \mathrm{mosm} / \mathrm{kg}, \mathbf{P}<0.001$, Mann-Whitney U test).

When all patients were considered, a negative correlation was found between plasma sodium concentration and both the serum concentration and daily dose of carbamazepine. Although this was significantly different from zero $(P<0.005)$, the multiple correlation coefficients were low $(-0.35$ and -0.34 respectively), which meant that only a small proportion of the interindividual variation in plasma sodium concentration was explained by the regression line. However, when plasma sodium concentration values were plotted against serum carbamazepine concentration in the 13 patients treated with carbamazepine alone (Fig. 3), a considerably higher coefficient of correlation was found $(-0.78, \mathrm{P}<0.002)$. No significant correlation could be found between serum carbamazepine concentration and plasma osmolality.

Age, sex, and duration of treatment did not appear to influence plasma sodium concentration.

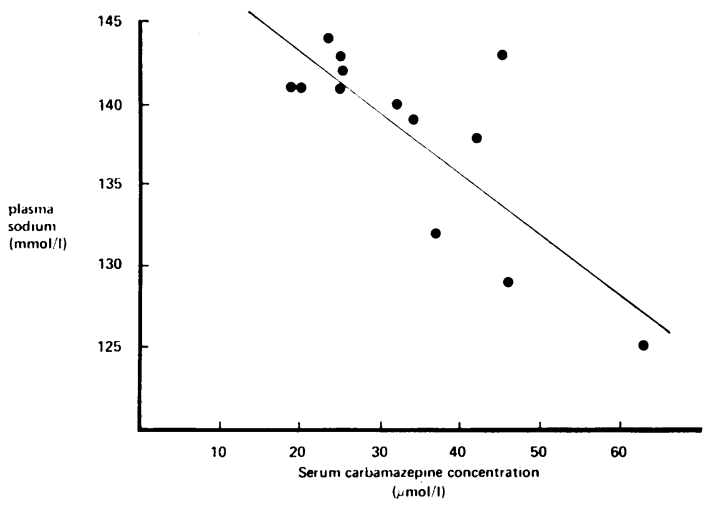

Fig. 3 Serum carbamazepine and plasma sodium concentrations in 13 patients treated with carbamazepine alone; $r=-0.78, P<0.002$.

In six patients the serum carbamazepine concentration exceeded the upper limit of the therapeutic range of $16-40 \mu \mathrm{mol} / 1$. Four of them were on monotherapy and two were hyponatraemic. There was a significant correlation between daily dose and serum carbamazepine concentration but the values were widely scattered (Fig. 4).

No signs suggestive of water intoxication were observed in the hyponatraemic patients, apart from drowsiness and confusion in one which could have been caused by concurrent drug intoxication. These signs cleared when the hyponatraemia was corrected by reducing the dose of carbamazepine. In the remaining patients, the electrolyte disturbance was corrected by administering frusemide $80 \mathrm{mg}$ daily. An improvement in the control of seizures followed frusemide administration in one.

WATER LOAD TESTS

Free water clearance values (mean \pm SD) determined over 30 min periods after oral administration of a water load in both healthy subjects and epileptic patients are shown in Fig. 5. Thirty minutes after the start of the test, the free water clearance reversed from negative to positive in all

Table Details of hyponatraemic patients

\begin{tabular}{|c|c|c|c|c|c|c|c|c|}
\hline \multirow[t]{2}{*}{ Subject } & \multirow[t]{2}{*}{ Sex } & \multirow{2}{*}{$\begin{array}{l}\text { Age } \\
(y r)\end{array}$} & \multicolumn{3}{|c|}{ Carbamazepine treatment } & \multirow{2}{*}{$\begin{array}{l}\text { Plasma } \\
\text { sodium } \\
\text { concentration } \\
(\text { mmolll })\end{array}$} & \multirow{2}{*}{$\begin{array}{l}\text { Plasma } \\
\text { osmolality } \\
(\mathrm{mosm} / \mathrm{kg})\end{array}$} & \multirow{2}{*}{$\begin{array}{l}\text { Other drugs } \\
(m g / \text { day })\end{array}$} \\
\hline & & & $\begin{array}{l}\text { Dose } \\
m g / k g / d a y\end{array}$ & $\begin{array}{l}\text { Duration of } \\
\text { treatment } \\
\text { (months) }\end{array}$ & $\begin{array}{l}\text { Serum } \\
\text { level } \\
(\mu \mathrm{mol} / \mathrm{l})\end{array}$ & & & \\
\hline $\begin{array}{l}1 \\
2 \\
3 \\
4 \\
5\end{array}$ & $\begin{array}{l}\mathbf{M} \\
\mathbf{M} \\
\mathbf{M} \\
\mathbf{F} \\
\mathbf{M}\end{array}$ & $\begin{array}{l}37 \\
33 \\
49 \\
27 \\
33\end{array}$ & $\begin{array}{r}13.6 \\
19.7 \\
14.6 \\
26.6 \\
9.5\end{array}$ & $\begin{array}{r}62 \\
3 \\
8 \\
4 \\
54\end{array}$ & $\begin{array}{l}37 \\
63 \\
24 \\
46 \\
28\end{array}$ & $\begin{array}{l}132 \\
125 \\
128 \\
129 \\
134\end{array}$ & $\begin{array}{l}256 \\
253 \\
266 \\
272 \\
274\end{array}$ & $\begin{array}{l}- \\
\overline{\text { Phenytoin }} 400 \\
\overline{\text { Phenytoin } 200} \\
\text { Nitrazepam } 5\end{array}$ \\
\hline
\end{tabular}




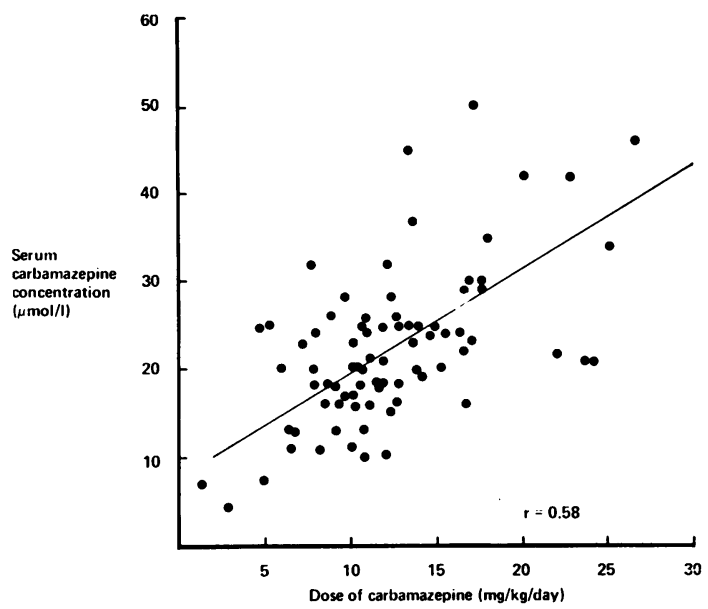

Fig. 4 Serum carbamazepine concentration and drug dose in the patients included in the trial; $r=0.58, P<0.001$.

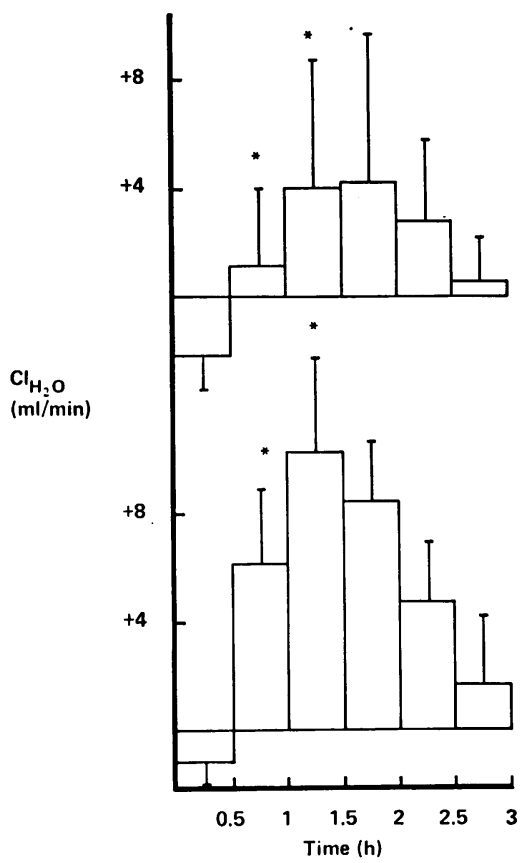

Fig. 5 Free water clearance (mean $\pm S D$ ) after administration of a water load in six epileptic patients (top) and six normal subjects (bottom). The asterisks indicate a statistically significant difference $(P<0.05)$ between the two groups, calculated by Student's $t$ test.

subjects studied, with the exception of two epileptic patients in whom it remained negative throughout the period of the test. In carbamazepine-treated patients average values were two to three times lower than those observed in healthy subjects. The difference was statistically significant at 0.5 and $1.0 \mathrm{~h}$ after the start of the test. All normal subjects showed a similar response to the water load, but marked interindividual differences were found among the patients. Two of the patients had a normal response, while in two (one of whom is illustrated in Fig. 6) the free water clearance showed little or no change after the water load. In these two subjects plasma sodium concentration and osmolality were found to be low in the sample taken at the end of the test; the remaining four patients and the six control subjects had normal values. The two hyponatraemic patients complained of malaise and drowsiness and one had an epileptic attack at the end of the test. In each, a marked diuretic response followed the oral administration of $80 \mathrm{mg}$ of frusemide (Fig. 6).

\section{Discussion}

Carbamazepine has been shown to have an antidiuretic effect in patients with diabetes insipidus (Kimura et al., 1974; Meinders et al., 1974; Wales, 1975; Smith et al., 1977), trigeminal neuralgia (Rado, 1973; Henry et al., 1977; Stephens et al., 1977), and epilepsy (Ashton et al., 1977; Henry et al., 1977; Stephens et al., 1977). It has been suggested that the drug acts by stimulating the release of antidiuretic hormone (ADH) from the posterior pituitary (Ashton et al., 1977), although present evidence remains controversial (Kimura et al., 1974; Meinders et al., 1974; Wales, 1975; Smith et al., 1977). Our study confirms that hyponatraemia and hypo-osmolality may occur during carbamazepine treatment of patients with epilepsy. Although no reports are available in a population

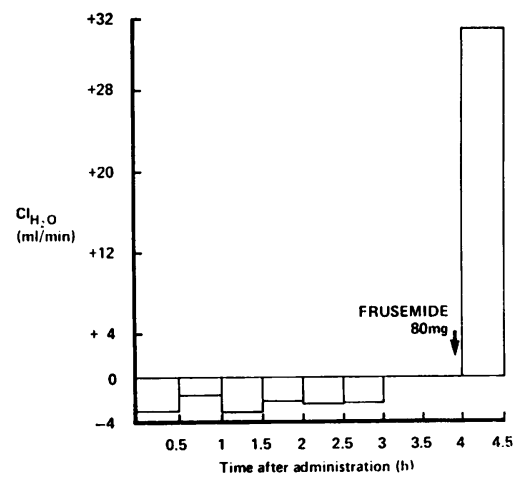

Fig. 6 Free water clearance after administration of a water load in a 26 year old epileptic man. Note the marked response to $80 \mathrm{mg}$ of oral frusemide. 
of a similar size, a study by Henry et al. (1977) in which an attempt was made to estimate the incidence of electrolyte abnormalities in adult patients suggested that these may occur in as many as onethird. Hyponatraemia, however, was not observed in any of the 28 children studied by Helin et al. (1977). In our patients the negative correlation between plasma sodium concentration and both the dose and serum concentration of carbamazepine, as described by Henry et al. (1977), was confirmed. However, hyponatraemia was found in a considerably smaller proportion of our patients. A possible explanation for the discrepancy is that, in all but six of our patients, serum carbamazepine concentration was below the upper limit of the therapeutic range of $16-40 \mu \mathrm{mol} / 1$. At the Chalfont Centre for Epilepsy, the determination of serum carbamazepine concentration forms part of the clinical management, and the dose of the drug is usually tailored to achieve a concentration within the therapeutic range. Since there is evidence that water intoxication tends to be associated with toxic serum concentration (Ashton et al., 1977; Henry et al., 1977; Stephens et al., 1977), the practice of drug monitoring has probably reduced the incidence of this adverse effect in our population. It is of interest in this respect that in none of the epileptic children studied by Helin et al. (1977) was the serum carbamazepine concentration clearly toxic, which may account for their negative findings.

The serum concentrations of carbamazepine in our patients were lower than those observed by Henry et al. (1977) in spite of a similar dose range in the two series. This was probably due to the fact that most of our patients were receiving other antiepileptic drugs and these agents lower serum carbamazepine concentration by inducing its metabolism (Christiansen and Dam, 1973). Four $(31 \%)$ of the 13 patients on a single drug ("monotherapy") had toxic concentrations compared with only two $(3 \%)$ of the patients on more than one drug ("polytherapy"), in spite of similar daily dosages administered to the subjects of both groups. Henry et al. (1977) did not mention the time of sampling although it is known that serum carbamazepine concentration fluctuates widely during the day even when the drug is administered in divided daily doses (Johannessen et al., 1976). Samples were taken from our patients before the first morning dose when the concentration is generally at a trough (Johannessen et al., 1976). The correlation between serum concentration and dose found by us has not been observed by others (Pynnönen et al., 1977). However, the values showed a large scatter around the regression line probably because of interindividual differences in absorption and rate of metabolism.

The observation that hyponatraemia was more frequent in the patients on monotherapy and that plasma sodium and serum carbamazepine concentrations correlated more strongly in these patients suggests that other antiepileptic drugs may prevent the antidiuresis induced by carbamazepine. This antagonism may be the result of a combined pharmacokinetic and pharmacodynamic interaction - that is, reduction of serum carbamazepine concentration, as discussed above, and inhibition of ADH release from the posterior pituitary, an effect which has been documented with phenytoin (Fichman et al., 1970).

The number of patients with hyponatraemia was too small for the effect of this disturbance on fit frequency to be assessed. In one patient the correction of hyponatraemia appeared to improve seizure control, but this could equally have been due to the anticonvulsant properties of frusemide (Ahmad et al., 1976). However, the relationship between epilepsy and water balance appears established (McQuarrie, 1929). Fluid restriction has been successfully employed in the treatment of epilepsy (Stubbe-Teglbjaerg, 1936), whereas forced water intake has been used as a diagnostic test to produce seizures (McQuarrie and Peeler, 1931). This might have been responsible for the prolonged fit in one of our patients who developed hyponatraemia after the water load test. Although the incidence of hyponatraemia in epileptic patients treated with carbamazepine is probably relatively small, many patients may be susceptible to electrolyte disturbance. Our results show that even if carbamazepine-treated subjects have a normal plasma sodium concentration and osmolality, their capacity to excrete a water load may be grossly impaired. Therefore, excessive intake of fluids-for example, several pints of beershould be particularly discouraged in patients taking the drug. We suggest that plasma sodium concentration and osmolality should be checked when symptoms like lethargy, drowsiness, and confusion or an unexplained increase in fit frequency develop in carbamazepine-treated patients, especially when the dose or the serum concentration of the drug is high. Our experience suggests that monitoring the serum concentration of carbamazepine is a valuable supplement to clinical judgment in enhancing therapeutic efficacy and reducing the incidence of adverse effects.

We thank Dr John Laidlaw, Senior Physician at the Chalfont Centre for Epilepsy, for allowing us to study his patients, $\mathrm{Dr}$ J. R. Rawstron for advice 
on electrolyte measurements, and Mrs Jane Wadsworth for statistical assistance.

Note added in proof Stephens et al. (1978) have demonstrated abnormal water metabolism in 10 out of 12 volunteers given carbamazepine.

\section{References}

Ahmad, S., Clarke, L., Hewett, A. J., and Richens, A. (1976). Controlled trial of frusemide as an antiepileptic drug in focal epilepsy. British Journal of Clinical Pharmacology, 3, 621-625.

Ashton, M. G., Ball, S. G., Thomas, T. H., and Lee, M. R. (1977). Water intoxication associated with carbamazepine treatment. British Medical Journal, 1, 1134-1135.

Christiansen, J., and Dam, M. (1973). Influence of phenobarbital and diphenylhydantoin on plasma carbamazepine levels in patients with epilepsy. Acta Neurologica Scandinavica, 49, 543-546.

Fichman, M. P., Kleeman, C. R., and Bethune, J. E. (1970). Inhibition of antidiuretic hormone secretion by diphenylhydantoin. Archives of Neurology (Chicago), 22, 45-53.

Helin, I., Nilsson, K. O., Bjerre, I., and Vegfors, P. (1977). Serum sodium and osmolality during carbamazepine treatment in children. British Medical Journal, 2, 558.

Henry, D. A., Lawson, D. H., Reavey, P., and Renfrew, S. (1977). Hyponatraemia during carbamazepine treatment. British Medical Journal, 1, 83-84.

Johannessen, S. I., Gerna, M., Bakke, J., Strandjord, R. E., and Morselli, P. L. (1976). CSF concentrations and serum protein binding of carbamazepine and carbamazepine-10-11-epoxide in epileptic patients. British Journal of Clinical Pharmacology, 3, 575-582.

Kimura, T., Matsui, K., Sato, T., and Yoshinaga, K. (1974). Mechanism of carbamazepine (Tegretol)induced antidiuresis: evidence for release of anti- diuretic hormone and impaired excretion of a water load. Journal of Clinical Endocrinology and Metabolism, 38, 356-362.

McQuarrie, I. (1929). Epilepsy in children. The relationship of water balance to the occurrence of fits. American Journal of Diseases in Childhood, 38, 451-467.

McQuarrie, I., and Peeler, D. B. (1931). The effects of sustained pituitary antidiuresis and forced water drinking in epileptic children. Journal of Clinical Investigation, 10, 915-940.

Meinders, A. E., Cejka, V., and Robertson, G. L. (1974). The antidiuretic action of carbamazepine in man. Clinical Science and Molecular Medicine, 47, 289-299.

Pynnönen, S., Sillanpäa, M., Frey, H., and Iisalo, E. (1977). Carbamazepine and its 10, 11-epoxide in children and adults with epilepsy. European Journal of Clinical Pharmacology, 11, 129-133.

Rado, J. P. (1973). Water intoxication during carbamazepine treatment. British Medical Journal, 3, 479.

Smith, N. J., Espir, M. L. E., and Baylis, P. H. (1977). Raised plasma arginine vasopressin concentration in carbamazepine-induced water intoxication. British Medical Journal, 2, 804.

Stephens, W. P., Espir, M. L. E., Tattersall, R. B., Quinn, N. P., Gladwell, S. R. F., Galbraith, A. W., and Reynolds, E. H. (1977). Water intoxication due to carbamazepine. British Medical Journal, 1, 754755.

Stephens, W. P., Coe, J. Y., and Baylis, P. H. (1978). Plasma arginine vasopressin concentrations and antidiuretic action of carbamazepine. British Medical Journal, 1, 1445-1447.

Stubbe-Teglbjaerg, H. P. (1936). Investigations on epilepsy and water metabolism. Acta Psychiatrica Neurologica, 9, 1-247.

Wales, J. K. (1975). Treatment of diabetes insipidus with carbamazepine. Lancet, 2, 948-951. 